\title{
Behaviour and fate of metals in urban wastewater treatment plants: a review
}

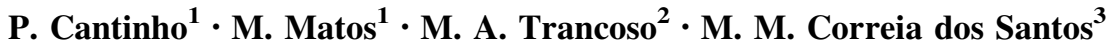

Received: 2 March 2015/Revised: 3 August 2015 / Accepted: 2 September 2015

(C) Islamic Azad University (IAU) 2015

\begin{abstract}
The concerns on metals in urban wastewater treatment plants (WWTPs) are mainly related to its contents in discharges to environment, namely in the final effluent and in the sludge produced. In the near future, more restrictive limits will be imposed to final effluents, due to the recent guidelines of the European Water Framework Directive (EUWFD). Concerning the sludge, at least seven metals (Cd, $\mathrm{Cr}, \mathrm{Cu}, \mathrm{Hg}, \mathrm{Ni}, \mathrm{Pb}$ and $\mathrm{Zn}$ ) have been regulated in different countries, four of which were classified by EUWFD as priority substances and two of which were also classified as hazardous substances. Although WWTPs are not designed to remove metals, the study of metals behaviour in these systems is a crucial issue to develop predictive models that can help more effectively the regulation of pre-treatment requirements and contribute to optimize the systems to get more acceptable metal concentrations in its discharges. Relevant data have been published in the literature in recent decades concerning the occurrence/fate/behaviour of metals in WWTPs. However, the information is dispersed and not standardized in terms of parameters for comparing results. This work provides a critical review on this issue through a careful systematization, in tables and graphs, of the results reported in the literature, which allows its comparison and so its analysis, in order to conclude about the state of the art in
\end{abstract}

P. Cantinho

pcantinho@deq.isel.ipl.pt

1 Department of Chemical Engineering, Instituto Superior de Engenharia de Lisboa, R. Conselheiro Emídio Navarro, 1949-014 Lisbon, Portugal

2 Laboratory of Biofuels and Environment, National Laboratory of Energy and Geology, Estrada do Paço do Lumiar, 22, Ed. E, 1649-038 Lisbon, Portugal

3 Center of Structural Chemistry, Instituto Superior Técnico, Av. Rovisco Pais, 1049-001 Lisbon, Portugal this field. A summary of the main consensus, divergences and constraints found, as well as some recommendations, is presented as conclusions, aiming to contribute to a more concerted action of future research.

Keywords Metals removal mechanisms - Metals mass balances - Metals behaviour models - Priority pollutants . Sewage sludge metals content - Urban wastewater metals sources

\section{Introduction}

Metals and its compounds are of great concern, even at trace levels, primarily due to their potential toxicity to all aspects of the environment. The risks of their bioaccumulation in the food chains pose one of the major environmental and health problems of our modern society (Mudho and Kumar 2013). Being natural components of the Earth's crust, most metals present a background concentration. Thus, the anthropogenic emissions, which promote the increase in natural concentrations and its transport to different environmental compartments, are the ones of major concern. Trace quantities of many metals are found in sewage from various sources. Among them, arsenic (As), cadmium (Cd), chromium $(\mathrm{Cr})$, cooper $(\mathrm{Cu})$, mercury $(\mathrm{Hg})$, nickel $(\mathrm{Ni})$, lead $(\mathrm{Pb})$ and zinc $(\mathrm{Zn})$ are classified as potentially toxic elements, which mean that depending on the concentration and time of exposure, they can pose problems of acute or chronic human health effects, carcinogenicity, phytotoxicity and bioaccumulation (EC 2001a, b).

Municipal wastewater treatment plants (WWTPs) are not designed for metals removal. Despite the fact that for a long time, it has been reported that metals were significantly removed from the final effluents, its removal is in most of the 